\title{
INVESTIGATING THE STATE OF PLAY OF GEOBIM ACROSS EUROPE
}

\author{
C. Ellul ${ }^{1}$, J. Stoter ${ }^{2}$, L. Harrie ${ }^{3}$, M. Shariat ${ }^{3}$, A. Behan ${ }^{4}$, M. Pla ${ }^{5}$ \\ ${ }^{1}$ Department of Civil, Environmental and Geomatic Engineering, University College London, London, UK, - c.ellul@ucl.ac.uk \\ 23D Geoinformation, Delft University of Technology, Delft \& Kadaster Apeldoorn, The Netherlands, j.e.stoter@tudelft.nl \\ ${ }^{3}$ Department of physical geography and ecosystem science, Lund University, Lund, Sweden- lars.harrie@nateko.lu.se, \\ masoome.shariat@gmail.com \\ ${ }^{4}$ School of Multidisciplinary Technologies, College of Engineering \& Built Environment, Dublin Institute of Technology, Dublin, \\ Ireland - avril.behan@dit.ie \\ ${ }^{5}$ Institut Cartogràfic i Geològic de Catalunya, Barcelona, Catalonia, maria.pla@icgc.cat
}

KEY WORDS: BIM, GIS, Interoperability, GeoBIM, Research Challenges, interoperability, data integration, National Mapping and Cadastral Agency

\begin{abstract}
:
In both the Geographic Information (Geo) and Building Information Modelling (BIM) domains, it is widely acknowledged that the integration of data from both domains is beneficial and a crucial step in facing the multi-disciplinary challenges of our built environment. The result of this integration - which can broadly be termed GeoBIM -could answer questions such as identifying an appropriate Heating, Ventilation and Air Conditioning system for a building based on room usage, outside air temperature, solar exposure and traffic pollution or validating whether a proposed built asset meets relevant planning constraints.

Developing a coherent approach to GeoBIM integration requires consensus between multiple stakeholders from both the Geo and the BIM side and at an international level. This multi-country and multi-stakeholder approach is the topic of a 2-year EuroSDR project on GeoBIM integration that started in November 2017. The general aim of the project is to detail both the needs and the issues of GeoBIM integration, studied from use cases as well as from existing experiences in the participating countries and to develop initial solutions accordingly. This paper reports initial results - it identifies strong potential for GeoBIM but also rather fragmented activity, with no national level focus. It also notes that research (both in industry and academia) primarily focuses on standards, interoperability and data integration or exchange. Based on these findings - and with a focus on existing work and topics of interest to NMCAs - the next phase of the work will develop more detailed case studies for Asset Management and Urban Planning.
\end{abstract}

\section{INTRODUCTION}

Building Information Modelling (BIM) is, amongst other things ${ }^{1}$, "a modelling technology that combines the design and visualization capabilities of CAD (Computer Aided Design) with the rich parametric object and attribute modelling of Geographical Information Systems (GIS)" and unlike CAD (Computer Aided Design) entities are meaningful Casey and Vankadara (2010). Worboys and Duckham (2004) define a GIS as a "computer-based information system that enables capture, modelling, storage, retrieval, sharing, manipulation, analysis, and presentation of geographically referenced data".

BIM and GIS can, at first glance, appear similar (see Section 2.1) - they both model the real world, with particular focus on the built environment. However, this similarity masks some important differences that arise from the main motivation for their original development, and their resulting intended purpose. GIS were originally developed in the late 1960s to support land management and related tasks. In parallel with this, CAD began to be used by architects and civil engineers for building and infrastructure design. Key differences include use of local or global coordinate systems. GIS also offers generic analysis whereas BIM is mostly focused on construction (see Section 2.1 for a detailed review).

These similarities and differences have driven a large number of investigations into how the two sources of information about the built environment can be used together, in particular given increasing interest on the GIS side in 3D modelling, on the BIM side in enriching outdoor information and the cost - on both sides
- of data capture. In addition, in both the GIS and BIM domains, it is widely acknowledged that the integration of data from both domains is beneficial and a crucial step in facing the multidisciplinary challenges of the built environment.

The result of this integration - which can broadly be termed GeoBIM -could answer questions such as identifying an appropriate HVAC (Heating, Ventilation, Air Conditioning) system for a building based on room usage, outside air temperature, solar exposure and traffic pollution or validating whether a proposed built asset meets relevant planning constraints and support tasks that include logistics for construction, asset management, facilities upgrades, road safety design improvements amongst many more (see Section 2.3.1 for examples). In this context, the term integration is used very broadly - i.e. to indicate the combination of two or more sources of data into one system, to underpin analysis and/or visualisation that then makes use of both these sources.

However, while GeoBIM could underpin many applications, there are also challenges to be overcome to enable these data sources to be integrated and achieve their full potential.

Developing a coherent approach to GeoBIM integration requires consensus between multiple stakeholders from both the GIS and the BIM side, working at an international level. Developing such a multi-country and multi-stakeholder approach is the topic of a 2-year EuroSDR (European Spatial Data Research, which brings together National Mapping and Cadastral Agencies - NMCAs and researchers across Europe) project on GeoBIM integration that started in November 2017. The project involves eleven

\footnotetext{
${ }^{1}$ For example, BIM also focusses on workflow and managerial aspects relating to construction but these are not considered here.
} 
participating National Mapping and Cadastral Agencies, and four academic institutions (see list of participants in the Acknowledgements section) with regional or national responsibility. Motivation for participating can be summarised in Figure 1 (note that some of the organisations listed multiple motivations) and range from an interest in the technical/interoperability aspects of the problem, to a wish to explore the potential of BIM as a data source for a 3D dataset. Some NMCAs have also recognised that, in situations where BIM is nationally mandated, a vast quantity of BIM data will be available that will require curation to enable downstream use, and recognize that this may align with their current role as national repositories of geospatial data.

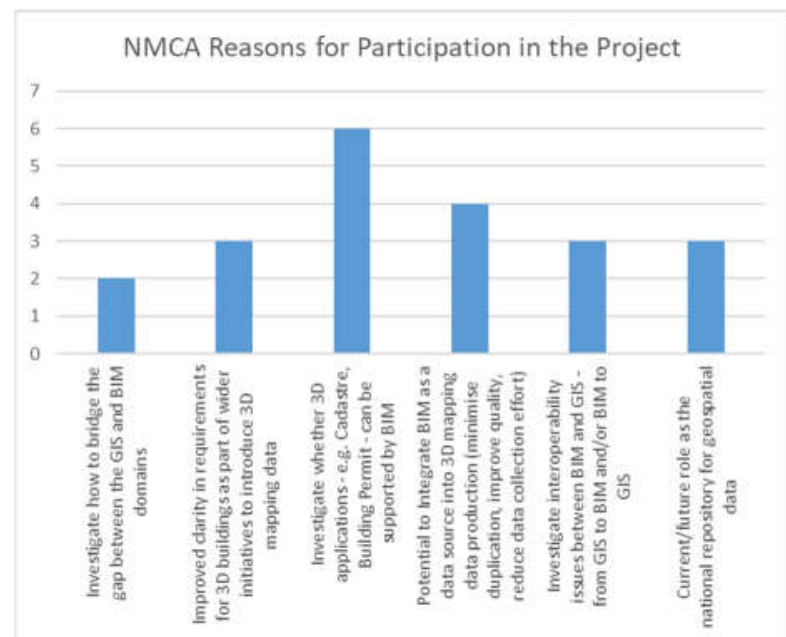

Figure 1 - NMCA Motivation for Participating in the EuroSDR GeoBIM Project

The project is divided into two phases, with the first phase described in this paper - aiming to identify the current status, prospects and challenges for GeoBIM integration in the participating countries, and from that set an initial research agenda that can underpin the second phase of the project. Thus, the remainder of this paper addresses the question: from $a$ National Mapping and Cadastral Agency perspective, what are the key benefits of GeoBIM integration, and what are the key challenges to be addressed to achieve them?

\section{BACKGROUND}

There has been a significant amount of research and development firstly in the GeoCAD (integration of GIS and CAD) field and more recently in GeoBIM. Aspects of this research are summarised here.

\subsection{Similarities and Differences between BIM and GIS}

BIM and GIS are both special cases of information systems (Lee, et al., 2006), and key similarities are summarised by Ellul et al (2015). Both can model the built environment in 3D and both can model both indoor and outdoor features within this environment. Additionally, both BIM and GIS data can be managed in a Database Management System. They both provide efficient methods for the documenting, editing, managing and visualising spatial and non-spatial information, and both can represent the world 'as is' and also model historic data and future planning and modelling outcomes, and model data at varying scales and levels of detail.
Ellul et al (2015) also summarise key differences: a focus on detailed engineering modelling (BIM) versus less detail, larger area (GIS), millimetre measurement units (BIM) versus meter (GIS). GIS describes buildings, entire sites, regions or countries whereas BIM focuses on projects at local scale. BIM is initiated during procurement phase of facility lifecycle, focussed on built environment and construction, GIS has a much wider-ranging focus. BIM is used to organise information to specific contractual deliverables, GIS can organise multiple types of information, and integrate spatial and non-spatial information. Very sophisticated 3D geometry can be modelled in BIM (B-Rep, NURBS, Splines and CSG), GIS supports far less sophisticated geometry primarily on construction materials but can model a much wider range of geometry, attributes and also supports sophisticated spatial analysis. BIM offers basic database integration, whereas GIS can be fully integrated with relational databases. Local coordinate systems are generally used in BIM, whereas GIS uses regional, national or global coordinate systems.

\subsection{Key Standards - IFC and CityGML}

The IFC (Industry Foundation Classes) exchange format was developed by the International Alliance for Interoperability (now known as buildingSMART) and provides a formalised representation of typical building components, e.g. wall, door, and their attributes, e.g. type, function, geometric description, relationships. It also supports topological information (e.g. "connected to") and abstract concepts such as schedules, activities and construction costs (Casey and Vankadara 2010). Objects are grouped into logical entities (classes, with properties such as name, materials, relationships, constraints) and product information is grouped according to construction trade (Casey and Vankadara 2010). Full details of the IFC standard can be found on the buildingSMART website (https://www.buildingsmart.org/).

CityGML is an open data model for the storage and exchange of 3D city models, based on Geography Markup Language version 3.1.1 (GML3) and is an Open Geospatial Consortium standard. The aim of the development of CityGML is to reach a common definition of the basic entities, attributes, and relations of a 3D city model. It currently defines a number of Levels of Detail for the 3D City Model, where the coarsest level LOD0 is essentially a two and a half dimensional Digital Terrain Model over which an aerial image or a map may be draped. Buildings may be represented in LOD1 as a block model, with flat roofs, moving up to LOD4 which describes interior structures for buildings including rooms, interior doors, stairs, and furniture. In all LODs appearance information such as high resolution textures can be mapped onto the structures.

\subsection{Integrating BIM and GIS}

\subsubsection{Potential Benefits of Integration}

A number of applications have been identified in the literature as having potential benefit from the ability to transfer data between BIM and GIS. Some of these are described at high level, and additional detail about two key applications is provided building permits and cadastral mapping - where more substantial research has been carried out and which are of particular interest to NMCAs.

Fosu et al (2015) note that 15 individual journals and 10 conferences were publishing on this topic in 2013 including applications related to: emergency situations and disaster management, navigation, climate change, energy management and visualisation of utilities. Specific examples include 
calculating material quantities needed (BIM), routing materials to site (GIS), and then finding a location to store them on site (BIM) in the context of minimising disturbance caused by construction projects (Rizal et al 2013). A similar application is identified by Javier et al (2013) for construction supply chain management. Identifying indoor wayfinding points (BIM) and outdoor wayfinding points (GIS) for seamless routing and navigation has been identified as a second application (Liu et al 2017). Use of GeoBIM in emergency response situations was described by Bogulawski et al (2015).

A key area that could benefit from GeoBIM is Asset and Facilities Management. For example, Boyes et al (2017) describe work carried out to migrate BIM data for a large engineering/railway project (Crossrail, in the UK) which would allow railway managers to have access to detailed digital models describing the assets - signals, electrical fittings and the spaces in which these are enclosed. They note that there are two key issues that impede this vision from becoming reality - the underlying quality of the BIM in terms of pre-planning for Asset Management (i.e. tagging objects and ensuring that BIM data is structured for conversion and downstream use) and the difficulty of defining a space in an irregular environment such as a railway station (Boyes et al, 2017).

The building permit process involves both BIM data and geodata, the latter often in form of a situation plan or representing building regulations-related information such as $3 \mathrm{D}$ noise contour or maximum building height. To automate the process, integration of these two data sources is important. This could be performed by converting the geodata to the BIM environment (van Berlo et al. 2013) or by converting the BIM into to the geodata environment (Olsson et al. 2018). Both of these approaches allow automatic checking of building requirements (from a detailed development plan) such as densification level and building height. To automate this process the detailed development plans need to be in a computer readable standard. Some countries already have this type of detailed development standard, while in others this is still in a development phase (see e.g. Brasebin et al. 2016).

Cadastral Systems vary between countries, both with regard to legal aspects and with regard to technical aspects. To improve the exchange of cadastral information both with and between countries the Land Administration Domain Model (LADM) was developed (Lemmen et al. 2015, Kalogianni et al. 2017). It is a conceptual model that does not describe the technical implementation. Oldfield et al. (2017) study how BIM data, in form of IFC datasets, can be used to populate the LADM model. For this purpose, a subset of the IFC objects were used (using a Model View Definition). They concluded that the approach enabled exchange of boundary representations of topological (cadastre) objects capable of being combined into a 3D legal space overview map. El-Mekawy et al. (2015) study how BIM can be utilised for cadastral purposes, based on the unified building model (El-Mekawy and Östman 2012). They show how 3D cadastral boundaries can be imported to the BIM model as well as how BIM data can serve in the 3D cadastre process. BIM standards such as IFC does not natively support inclusion of cadastre information. To support cadastral information Atazadeh et al. (2017) propose an extension of the IFC standard that they also demonstrate in a test case. Stoter et al. (2016) describes an early $3 \mathrm{D}$ cadastre registration in the Netherlands. In their work they export the building model to legal spaces represented in a 3D PDF for e.g. visualisation. They conclude, among other findings, that more work is needed to formalise and standardise the process.

\subsubsection{General Approaches to Integration}

At a technical level, three broad approaches to integrating data from BIM and GIS into one system can be identified: using an ETL (extract, transform, load) procedure to take BIM data modelled as Industry Foundation Classes (see Section 2.2) into GIS; using ETL to transform GIS data - usually topographic mapping information - into BIM; identifying a neutral approach to model both data sources.

\subsubsection{Conceptual Mapping}

A key step towards GeoBIM is to define a conceptual mapping between the two dominant data schema. Kang (2018) describes the BIM-to-GIS conceptual mapping B2GM standard (ISO N19166) which defines the requirement and logical mapping for implementation of the two heterogeneous data models in the BIM and geospatial domain. In practice, such a mapping only works if the IFC models are indeed structured as such.

A second approach to this conceptual mapping has been explored by creating a GeoBIM extension for CityGML (deLaat and van Berlo, 2011). As not all cities use CityGML and an alternative approach, with some basing their City Model on INSIPRE, an INSPIRE-focussed approach has also been trialled in Sweden in their creation of the Svensk Geoprocess Model, even though their building model does not fully comply with the INSPIRE extension rules (see GCM 2014).

The various approaches of creating national standards for city models have led to a situation where the models are not fully compliant with each other (see a discussion about this in Eriksson et al. 2018)) concerning the building part elements, but this is also true for other feature types. This in turn results in additional challenges for the conceptual schema mapping process.

\subsubsection{Converting IFC to CityGML}

To date, converting data between the two dominant standards is the subject of the majority of research in the GeoBIM domain, with the majority of papers following the ETL route from IFC to CityGML. However, no perfect solutions have been identified for this process and there are also several problems in this conversion which make such a solution unlikely to be developed. Donkers et al. (2016) point out, among others, that different semantic information is attached to the geometric primitives in IFC and CityGML as well as that they use different geometric representations (CSG and B-Rep, see Abdul-Rahman and Pilouk 2007). An additional problem is that IFC allows many ways to model the same object (e.g. a turn in a staircase can be a landing or a stair component), which implies that it is hard to find a solution that can cope with all IFC models. However, there are several studies that provide appropriate solutions that at least work for certain conversion applications and datasets. Benner et al. (2005) described the general techniques going from IFC to a model similar to CityGML. Isikdag and Zlatanova (2009) provided a framework of how IFC objects can be used to generate CityGML objects in several LODs. de Laat and van Berlo (2011) describe the development of a CityGML extension - GeoBIM to transfer semantic IFC data into a GIS context. Donkers et al. (2016) develop an automatic conversion from IFC to CityGML LOD3 based on three steps: (1) the filtering and mappings of the semantics, (2) the 3D geometric transformations to extract the exterior envelope of a building, and (3) the refinements that ensure that the output is a valid CityGML file.

Arroyo et al (2017) and Boyes et al (2017) have experimented with converting real BIM data - generated by live projects - into GIS with the aim of creating guidelines for BIM modelling 
process to facilitate the transformation between CityGML and IFC. Both groups of authors note that some of the main issues encountered relate to the many incorrect geometric or topological objects within in the IFC data, which first need to be corrected before the transformation.

The Open Geospatial Consortium (2017) reached similar conclusions as part of a project examining the use of IFC and CityGML in Urban Planning. They identified inconsistencies in coding IFC elements that complicates the transformation to CityGML and conclude that in order to adopt IFC in Urban Planning, a clear set of specifications needs to be set for the preparation of IFC files.

\subsubsection{Software Options for Data Conversion}

A number of off-the-shelf software implementations also offer IFC to GIS conversions (although not addressing the above issues of incorrect geometry or inconsistent modelling). One such example is an extension to the open source BIMserver (BIMserver 2009), IfcExplorer CityGML Export (IfcExplorer 2007) and Safe FME scripts (Safe 2016). Other studies using the FME framework are presented by Floros et al. (2017) and Olsson (2018).

\section{METHODOLOGY}

At the beginning of the project, it was identified that, based on the knowledge of the project team, there were very varying levels of GeoBIM maturity across the participating countries. Given this context, and also given the multi-national, multi-lingual, multi-locational context of this research, a questionnaire was identified as the best approach to identifying the opportunities and challenges for GeoBIM.

Sharp et al. (2007) suggest that interviews and questionnaires are best used during the beginning and early part of a requirements gathering cycle. They also provide a quick and relatively cheap way to gather quantitative and qualitative data from a large group of people, particularly if they are self-administered. The process takes a relatively short period of time and the use of web-based questionnaires can allow for easy dissemination to the respondents. Questionnaires generate data that is easy to analyse. Limitations include the fact that participants may interpret questions differently, providing unreliable information. Further, the length of questionnaires can affect response rates, with longer questionnaires receiving lower responses (Roszkowski and Bean, 1990).

The questionnaire was initially designed by the project partners in a workshop organised in November 2017, and then refined in until February 2018 based on project partners' own experience.

The first section of the questionnaire asks for background information about the current status of BIM within the organisation and country - i.e. what are the drivers and who is involved. The second section focuses specifically on GeoBIM and is divided into subsections that include:

- Current status, awareness and activities relating to GeoBIM

- Relevant Standards, Research and Case Studies

- Opportunities and Challenges for GeoBIM - non technical

- Opportunities and Challenges for GeoBIM - technical

These questions are asked for two perspectives: a) the perspective of the organisation and b) the perspective of the region or country.
The questionnaire was circulated via the contact persons of the project - 11 in total - between March and April 2018. Based on the initial project meetings, it was understood prior to questionnaire distribution that flexibility was required in terms of its administration, due to the different levels of GeoBIM maturity across project partners. Thus, the questionnaire was completed using one or more of the following approaches: circulate the questionnaire to potential respondents using a snowballing approach; directly approach contacts in industry for a discussion, and complete the questionnaire based on the information given; directly approach colleagues within the NMCA, and complete the questionnaire based on their input; complete the questionnaire based on the personal knowledge of the EuroSDR representatives.

Once each national level questionnaire was completed, the responses were analysed and summarised, and commonalities and differences across the participant countries identified.

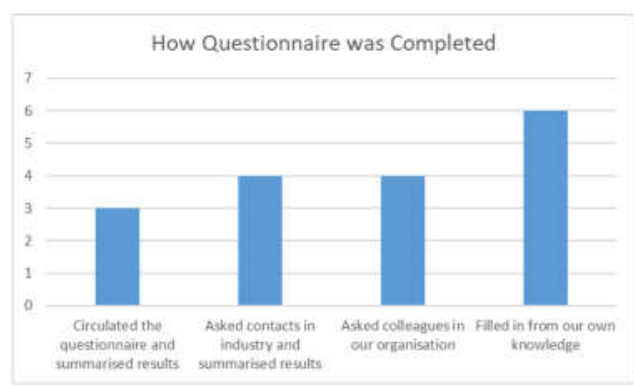

Figure 2 - Different approaches to questionnaire completion taken by the NMCAs

\section{RESULTS}

This section presents the results of the analysis of participants' responses to elicit current status of GeoBIM, standards and software, opportunities and challenges related to GeoBIM.

\subsection{Drivers for BIM (and hence GeoBIM)}

One of the key issues considered in the questionnaire was whether there were specific drivers for BIM at national level such as legislation. This would in turn give us an indication of the potential for GeoBIM related activities and the interest in the topic. Countries including the Netherlands, Denmark, the UK, France, Finland, Norway, Sweden, Catalonia and Ireland have existing or emerging BIM mandates, with other countries presenting a slightly more fragmented picture on the legal side e.g. mandates specific to one area such as buildings, or no legal mandate to date (Poland). Similarly, Switzerland report that they currently have few drivers for BIM.

\subsection{Current Status of GeoBIM}

In terms of the level of GeoBIM integration, a comparison between respondents was made at both organisational and regional/national level. For analysis at the organisation level, the organisations who responded to the questionnaire were categorised into mapping, cadastre and cartography, transportation, housing and building, and academia. Within the transport context, the Swedish Transport Administration reported most activities and within the housing context most activities were reported by the French Scientific and Technical Center of the Building (CSTB). Lund University and Institute for Virtual Design and Construction (FHNW) in Switzerland, report very similar levels of activity within the academic sector. 


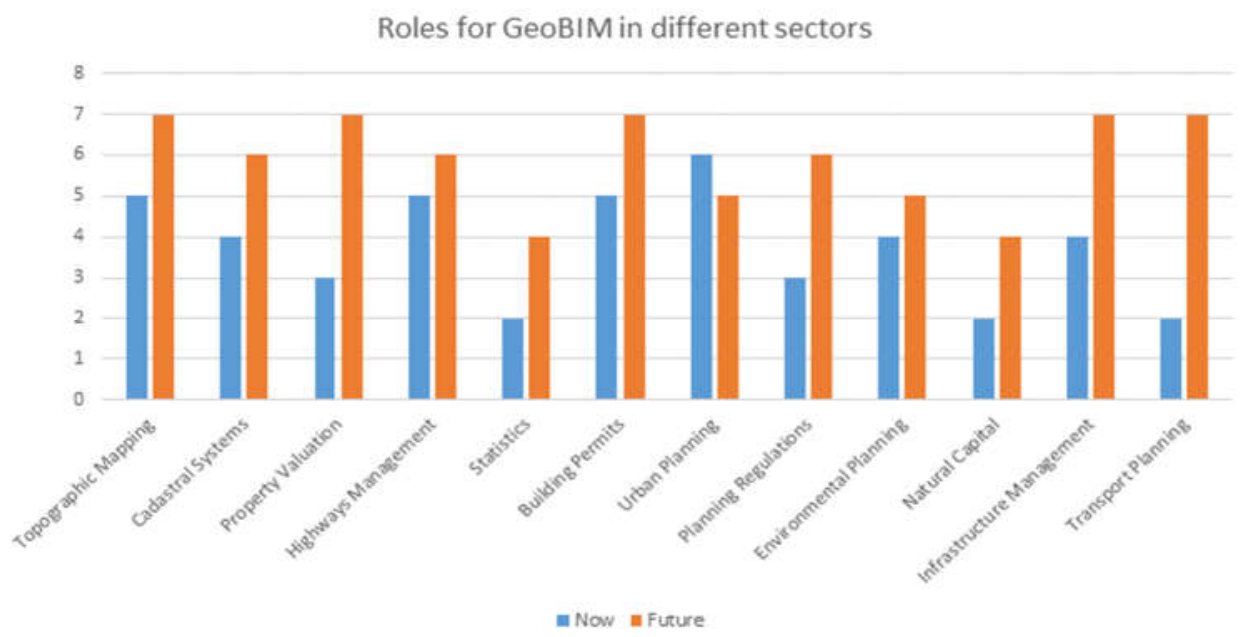

Figure 4 - Current and Future Opportunities for GeoBIM

Amongst the NMCAs the Norwegian Mapping Authority reports the highest number of GeoBIM-related activities.

A similar result can be noted regional/ country level. While Norway reports strategic activity at national, and the Netherlands, Sweden and Switzerland report ongoing activity at regional/national level, Poland and Ireland have limited awareness of the subject. Figure 3 provides details. None of the respondent countries reported 'no awareness or understanding'

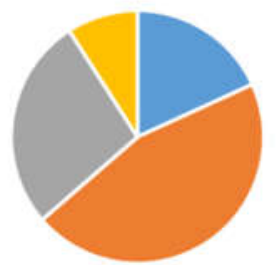

- Limited awareness (Ireland, Poland)

- A few small initiatives (Catalonia, Denmark, Finland, France, UK)

= Ongoing activity at regional/national level (Netherlands, Sweden, Switzerland)

n National level strategic activity (Norway)

Figure 3 - Level of GeoBIM Expertise within the NMCA

\subsection{Standards Related to GeoBIM}

CityGML (mentioned by eight NMCAs) and IFC (mentioned by seven NMCAs) are the most used international standards, followed by INSPIRE (mentioned by five NMCAs). While Finland uses all three, it seems that Poland is not aware of any GeoBIM related standards in their country.

\subsection{Opportunities for GeoBIM}

Respondents were asked - as an open question - to identify opportunities related specifically to their role as an NMCA. Improving existing production processes, and opportunities for increasing use of existing data products, were identified as an opportunity by five NMCAs, general improvement to urban and topographic mapping by two NMCAs, 3D cadastre by two NMCAs, avoiding duplicate data capture by one NMCA, improving building permit processes by one NMCA, Asset Management by one NMCA, change detection by one NMCA and opening new markets by one NMCA. Within academia, the EuroSDR academics participating in the project (four in total) reported that GeoBIM can bring together professionals and create joint teaching of surveyors, civil engineers, and architects. One respondent also mentioned the most important feature of GeoBIM that is combination of the geometric excellence of $\mathrm{BIM} / \mathrm{CAD}$ with the spatially-related semantic excellence of GIS as their benefit from the GeoBIM.

Opportunities identified at national level add to those identified with NMCA and academia, with respondents asked to identify application areas in their country where GeoBIM is currently applied or could be applied in future. Figure 4 summarises the results.

\subsection{Non-technical Challenges Preventing GeoBIM Uptake}

Due to fundamental differences between BIM and GIS (see Section 2.1), there are potentially significant barriers and challenges that need to be overcome before GeoBIM becomes a practical reality. The survey separated these into technical and non-technical challenges and respondents reported about these, both at organisational and national level.

From the perspective of all responding organisations, including mapping, transportation and building centres, lack of knowledge, expertise and focus on GeoBIM is the most common challenge encountered (four responses) closely followed by a lack of standards (three responses). Other challenges identified by individual respondents included lack of clarity of the role of an NMCA in the context of BIM, lack of significant BIM data coverage, lack of investment, lack of clarity of the role of BIM in existing tasks such as urban planning, lack of interoperability (e.g. with systems such as transport modelling) and the disciplinary divide between architects, engineers and geographers.

At the regional/country level, the key challenge identified by participant countries is the lack of awareness, knowledge, and expertise relating what GeoBIM is, especially among top-level decision makers (this was identified by eight countries). Lack of a national strategy, lack of investment and slow adoption of new technologies are another challenges, as is the current lack of available BIM data. Lack of coordination between GIS and BIM entities has led to a number of parallel initiatives sometimes carried out by competing entities. 


\subsection{Technical Challenges Preventing GeoBIM Uptake}

Lack of standards and knowledge, different data models, lack of suitable software, and inadequate BIM data are the main technical barriers to GeoBIM uptake identified by respondents at organisational level.

At national level, software incompatibility, different conceptual models and different standards are the challenges that have been pointed out most frequently, along with lack of knowledge and expertise. The absence of software which can support both BIM and Geo data, along with having GeoBIM capability is, overall, the most important major technical challenge of the stakeholders in different countries. Moreover, current BIM/GIS software is not interoperable, so integrating data at software level is challenging - for example, GIS packages are not able to handle the very complex detailed data from BIM. Different conceptual models are a vital technical challenge related to this issue, and there is a need for standards to support both BIM and GIS data.

\section{DISCUSSION}

This paper set out to answer the following question: from $a$ National Mapping and Cadastral Agency perspective, what are the key benefits of GeoBIM integration, and what are the key challenges to be addressed to achieve them?

Based on the initial research presented above, we identified that there are a number of key drivers for BIM - in particular legal initiatives at national level - that both highlight the opportunity for GeoBIM and also the necessity that such initiatives be aligned with current activities in spatial data management, as which generally fall under the responsibility - at least in part - by NMCAs. The range of opportunities identified for GeoBIM is good - top scoring opportunities included topographic mapping, property valuation, transport planning, building permits and infrastructure management, with related opportunities in cadastral systems, highways management and planning regulations coming a close second.

In terms of challenges, a key non-technical challenge was a current lack of understanding as to exactly what is involved in GeoBIM and the opportunities offered, with standardisation coming a close second. Standardisation issues, and lack of interoperability, were also identified as key technical challenges, perhaps reflecting the current research focus on this area. Due to interpretation during the modelling process, BIM models are far from standardised in their structures, even if they in theory comply with IFC, and cities are modelled differently. In general, the lack of common information models/structures on both the geospatial and the BIM side is an obstacle for the realisation of GeoBIM.

More generally the project team also noticed a sliding scale of GeoBIM maturity across the participant countries, with very varying levels of activity that - at least on the surface - seem to correspond with national legislation related to BIM. However, even in countries where BIM has been mandated for a while, there are as yet no national initiatives relating to GeoBIM. Projects are limited to those carried out by individuals or small groups, many of these being research related initiatives. This reflects what was identified in the literature (Section 2.3.4), where much of the research to date has been on individual small projects with a particular focus on converting IFC to GIS, with the latter frequently taking the form of CityGML. This fragmentation - and lack of national level GeoBIM initiatives - was observed in all the participating countries, although the level of activity was very varied.

\subsubsection{Interpreting the Results}

In all cases, the interpretation of the responses should take into account the methodology used for data capture. Feedback from the respondents, in general, indicated that the questionnaire was long and difficult to complete, as a result in particular of the open questions requesting details about GeoBIM projects or research. There is also an inherent bias in the responses as the questionnaires were issued through the NMCAs, who, to date, primarily have an interest in geographical information and hence have networks of respondents in this community rather than in the BIM community. Similarly, for those NMCAs who filled in the questionnaires from their own knowledge, it is likely that this knowledge was biased towards the geospatial side of the GeoBIM continuum. The different areas of responsibility national or regional - of the participating NMCAs may also have impacted the available responses given for the questions asked at national level. As noted in Section 3 questionnaires themselves also suffer from the possibility that questions can be misinterpreted - this is particularly the case in this project, where English is not the first language of many of the participants.

It should also be noted that although some opportunities and challenges were raised by one or a small number of respondents, there was general agreement amongst the group, during a meeting to discuss the results, that all the items identified were generally relevant multi-nationally although they may have different levels of importance in relation to the activities and focus of the different NMCAs.

\subsubsection{Identifying Next Steps for the Project}

The overall aim of the EuroSDR GeoBIM project is to detail both the needs and the issues of GeoBIM integration, studied from use cases as well as from existing experiences in the participating countries and to develop initial solutions accordingly. We are specifically interested how geospatial data that is produced by governmental agencies like NMCAs can be better utilised in design and building processes and in how NMCAs can benefit from increasing investment in, and governmental demand for, BIM.

The first phase of the project identified a number of key issues to be considered for phase 2, namely:

Addressing the lack of standards and interoperability between GIS and BIM. There are currently many different interpretations of the domain of "GeoBIM" and methods to convert BIM data into GIS data and vice versa each with their own pros and cons. However, for a fundamental solution supporting the life-cycle of objects, rather than ad-hoc conversion processes within individual projects and researches, BIM and GIS standards and a uniform and standardised transformation between them are required. This transformation should be based on a common view on how individual, highly detailed BIM-models can be best integrated in geo-databases that contain topographic and other location-related data at lower levels of detail and how the less detailed (at building or infrastructure level) but wider coverage, more contextual, broader range of information (both geometric and semantic) can be integrated into existing and future BIM.

Addressing the lack of awareness about GeoBIM and its Potential, and how it relates to current NMCA and BIM activities. In general, applications benefitting from GeoBIM can be identified by considering any application that combines 
geometric and semantic data about the built environment (sourced from GIS) with data about indoor structures or detailed engineering structures sourced from BIM. It is also important to note that, to date, many of the applications listed in Section 2.3.1 are theoretical or have only been explored in a research setting.

As there is ongoing activity - both through individual research projects and through more centralised activities such as the OGC- to address the interoperability challenge, the project team agreed that rather than duplicate this effort it would be more appropriate to address the challenges related to awareness, both within NMCAs and across other organisations both in government and in the private sector. Addressing this challenge would also allow us to take advantage of our existing national and international networks and strong existing links (through our role as NMCAs) with multiple representatives of the potential GeoBIM application areas outlined in Figure 4.

Therefore, the second phase of this project will develop a number of demonstrator projects to better communicate the potential of GeoBIM, both to GIS experts but equally importantly to those outside the discipline. Following a review of the questionnaire results, two sectors were identified as starting points for this activity - identifying how GeoBIM can improve existing planning/development permit processes (related to Urban Planning and Building Permits categories and potentially to Transport Planning in Figure 4), and identifying how GeoBIM could be used to support Asset Management (relevant for the Highways Management and Infrastructure Management categories). While Cadastral Systems was also considered as a potential area of interest, this was discarded as we were interested in identifying sectors that are relevant to all participating organisations/countries.

Within these two areas, we will therefore firstly be identifying common (i.e. relevant to all participating countries) steps and tasks undertaken, and from these generating overall process flow diagrams that represent, at a high level, each stage in the Planning Process and the general workflow undertaken within Asset Management. From these it should be possible to identify key points at which integrating both BIM and Geo data could be beneficial. Importantly, the participants in the project recognise that we are not experts in BIM or in these domains and will be partnering with experts through the project. Equally, given that one of the key questions raised by NMCAs within the project was to identify the potential use of their data and how BIM would integrate with this, the project will explore both the use of BIM within Geo and the use of Geo within BIM. This links back to the wider 'public task' of an NMCA - to support geo-related activities within a country, whether these be within the public or the private sector.

\section{CONCLUSION}

This paper presented results from the first Phase of a project investigating current and potential use of GeoBIM across a number of European countries, taken from an NMCA perspective. While very varying levels of GeoBIM maturity have been identified, it is clear that to date none of the participating countries are at a stage where there is a nationally coordinated GeoBIM activity. However, overall signs are encouraging - this project is one of similar ongoing initiatives at varying levels organisational, local, regional, national, international - and the work identified that there is strong focus on interoperability and the development of software for data exchange. There is also strong potential for the growth of GeoBIM in multiple sectors as more countries mandate BIM and hence more BIM data becomes available. In terms of technical integration, even though a situation has not yet been reached where this is easy to achieve it should be acknowledged that there has been much progress during the last two decades.

Importantly, the next phase of the project will focus on the use of BIM not only for construction (which has been a key focus to date, and where a key driver for BIM has been to reduce construction cost and improve construction efficiency) but also for operational tasks. This will in turn allow BIM to move out of the construction sector and towards a full life-cycle BIM, where maximum benefit can be achieved.

\section{ACKNOWLEDGEMENTS}

The authors would like to thank the participating EuroSDR organisations who are sponsoring this study: Agency for Data Supply and Efficiency Denmark, Kadaster, Netherland GUGiK Poland, IGN France, ICGC Catalonia, Kartverket Norway, Lantmateriet Sweden, NLS Finland, Ordnance Survey Ireland, Ordnance Survey UK and Swisstopo Switzerland and in particular the EuroSDR colleagues from each of these organisations who have contributed to the study design and execution as well as provided comments and feedback on this paper. The input of the participating Academic Institutions has also been fundamental to the success of this project: University College London, Dublin Institute of Technology, Lund University and Delft University of Technology.

\section{REFERENCES}

Abdul-Rahman A. and Pilouk M., 2007. Spatial Data Modelling for $3 D$ GIS, $2 D$ and $3 D$ Spatial Data Representations. Springer: Berlin, Germany.

Atazadeh, B., M. Kalantari, A. Rajabifard, S. Ho and T. Ngo, 2016. Building Information Modelling for High-rise Land Administration, Transactions in GIS, doi: 10.1111/tgis.12199.

Arroyo Ohori K., Biljecki F., Diakité A., Krijnen T.F., Ledoux H., and Stoter, J., 2017. Towards an integration of GIS and BIM data: What are the geometric and topological issues? ISPRS Annals of the Photogrammetry, Remote Sensing and Spatial Information Sciences, Vol. IV-4W5, pp. 1-8.

Benner J., Geiger A., and Leinemann K., 2005. Flexible generation of semantic 3D building models. In G. Gröger and T. $\mathrm{H}$. Kolbe, editors, In Proceedings 1st International Workshop on Next Generation 3D City Models, Bonn, Germany, pp. 17-22,

BIMserver, 2009. Linking BIM and GIS, http://bimserver.org/2009/08/27/linking-bim-and-gis/.

Boyes, G., Thomson, C., \& Ellul, C. (2015). Integrating BIM and GIS: Exploring the use of IFC space objects and boundaries. Proceedings of the GISRUK.

Brasebin, M., Perret, J., Mustière, S., Weber, C., 2016. A Generic Model to Exploit Urban Regulation Knowledge. ISPRS Int. J. Geo-Inf., 5(2), pp. 14-30.

Boguslawski, P., Mahdjoubi, L., Zverovich, V., Fadli, F., \& Barki, H., 2015. BIM-GIS modelling in support of emergency response applications. Building Information Modelling (BIM) in Design, Construction and Operations, 149, 381.

Boyes, G. A., Ellul, C., Irwin, D., 2017. Exploring BIM for Operational Integrated Asset Management-A Preliminary Study Utilising Real-world Infrastructure Data. ISPRS Annals of the Photogrammetry, Remote Sensing and Spatial Information Sciences. Vol. 4. No. 4W5. 
Casey, M. J., and Vankadara, S., 2010. Semantics in CAD/GIS Integration. CAD and GIS Integration, 143

de Laat R., and van Berlo L., 2011. Integration of BIM and GIS: The Development of the CityGML GeoBIM Extension. In: Kolbe T., König G., Nagel C. (eds) Advances in 3D Geo-Information Sciences. Lecture Notes in Geoinformation and Cartography. Springer, Berlin, Heidelberg.

Donkers S., Ledoux H., Zhao J. and Stoter J., 2016. Automatic conversion of IFC datasets to geometrically and semantically correct CityGML LOD3 buildings. Transactions in GIS, 2016, 20(4), pp. 547-569.

El-Mekawy, M., Östman, A., 2012. Feasibility of building information models for 3D cadastre in unified city models. [IJEPR]. International Journal of E-Planning Research, 1(4), 35-58. doi:10.4018/ijepr.2012100103

El-Mekawy, M., Paasch, J. and Paulsson, J., 2015. Integration of Legal Aspects in 3D Cadastral Systems, International Journal of E-Planning Research, 4(3), 47-71. doi: 10.4018/IJEPR.2015070103

Eriksson, H., L. Harrie and J. M. Paasch, 2017. What is the need for building parts? - A comparison of CityGML, INSPIRE Building and a Swedish building standard. In Proceedings of $3 D$ GeoInfo, Delft 1-2 October.

Floros G., Pispidikis I. and Dimopoulou E., 2017. Investigating Integration Capabilities Between IFC And CityGML Lod3 for 3d City Modelling. ISPRS Archives 42(4W7), pp. 1-6.

Fosu, Richelle, et al. "Integration of Building Information Modeling (BIM) and Geographic Information Systems (GIS)-a literature review and future needs." Proceedings of the 32nd CIB W78 Conference, Eindhoven, The Netherlands. 2015

GCM, 2014. INSPIRE Generic Conceptual Model, Version 3.4, http://inspire.ec.europa.eu/documents/inspire-genericconceptual-model (29 July 2018).

IfcExplorer, 2007. IfcExplorer CityGML Export. http://www.ifcwiki.org/index.php/IfcExplorer_CityGML_Expor t.

Isikdag U. and Zlatanova S., 2009. Towards Defining a Framework for Automatic Generation of Buildings in CityGML Using Building Information Models. In 3D Geo-Information Sciences; Lee J., Zlatanova, S., Eds.; Springer: Berlin, Germany, 2009; pp. 79-97.

Irizarry, J., Karan,I., and Jalaei, F., 2013, Integrating BIM and GIS to improve the visual monitoring of construction supply chain management. Automation in Construction 31 (2013): 241254.

Kalogianni E., Dimopoulou E., Quak W., Germann M., Jenni L., van Oosterom P., 2017. INTERLIS Language for Modelling Legal 3D Spaces and Physical 3D Objects by Including Formalized Implementable Constraints and Meaningful Code Lists. ISPRS Int. J. Geo-Inf., 6(10), pp. 319-355.

Kang, T., 2018. Development of a Conceptual Mapping Standard to Link Building and Geospatial Information. ISPRS Int. J. GeoInf., 7, pp. 162-183.

Lee, G., Sacks R., Eastman,C. M., 2006. Specifying Parametric Building Object Behavior (BOB) for a Building Information Modeling System, Automation in Construction 15(6) pp. 758776.

Lemmen C., van Oosterom P., Bennett R., 2015. The Land Administration Domain Model. Land Use Policy, 49, pp. 535545.
Liu, X., Wang, X., Wright, G., Cheng, J. C., Li, X., and Liu, R. 2017. A state-of-the-art review on the integration of Building Information Modeling (BIM) and Geographic Information System (GIS). ISPRS International Journal of GeoInformation, 6(2), 53.

OGC 2012 City Geography Markup Language (CityGML) Encoding Standard

Oldfield J., van Oosterom P., Beetz J., Krijnen T. F., 2017. Working with Open BIM Standards to Source Legal Spaces for a 3D Cadastre, ISPRS Int. J. Geo-Inf., 6(11), 351

Olsson P.-O. Conversion of an IFC-model to a lod2-3 3D-GIS building model. Agile conference, 12-15 June 2018, Lund, Sweden.

Olsson, P.-O., Axelsson, J., Hooper, M., Harrie, L., 2018. Automation of building permission by integration of BIM and geospatial data, Under review.

Roszkowski, M. J. and Bean, A. G. 1990. Believe it or not! Longer questionnaires have lower response rates. Journal of Business and Psychology, 4, 495-509.).

Sebastian, Rizal, Michel Böhms, and Pim van den Helm. "BIM and GIS for low-disturbance construction." Proceedings of the 13th International Conference on Construction Applications of Virtual Reality. 2013

Safe, $2016 . \quad$ BIM to GIS. https://knowledge.safe.com/articles/1024/bim-to-gis-advancedifc-lod-200-to-lod-3-citygml.html

Sharp, H., Rogers, Y., Preece, J. 2007. Interaction design: beyond human-computer interaction.

Stoter, J., Ploeger, H., Roes, R. van der Riet, E., Biljecki, F., Ledoux, H., 2016. First 3D Cadastral Registration of Multi-level Ownerships Rights in the Netherlands. 5th International FIG $3 D$ Cadastre Workshop, 18-20 October. https://www.fig.net/resources/proceedings/2016/2016 3dcadastr e/3Dcad_2016_37.pdf.pdf

van Berlo, L., Dijkmans, T., Stoter, J., 2013. Experiment for integrating Dutch 3d spatial planning and BIM for checking building permits. ISPRS Ann. Photogramm. Remote Sens. Spatial Inf. Sci. 2013, II-2/W1, 279-284. https://www.isprs-annphotogramm-remote-sens-spatial-inf-sci.net/II-2-

W1/279/2013/isprsannals-II-2-W1-279-2013.pdf

Smith, J., 1987a. Close range photogrammetry for analyzing distressed trees. Photogrammetria, 42(1), pp. 47-56.

Smith, J., 1987b. Economic printing of color orthophotos. Report KRL-01234, Kennedy Research Laboratories, Arlington, VA, USA.

Smith, J., 1989. Space Data from Earth Sciences. Elsevier, Amsterdam, pp. 321-332.

Smith, J., 2000. Remote sensing to predict volcano outbursts. In: The International Archives of the Photogrammetry, Remote Sensing and Spatial Information Sciences, Vol. XXVII-B1, pp. 456-469.

Worboys,,M., and Duckham, M., 2004. GIS: A Computing Perspective, $2^{\text {nd }}$ ed. CRC 